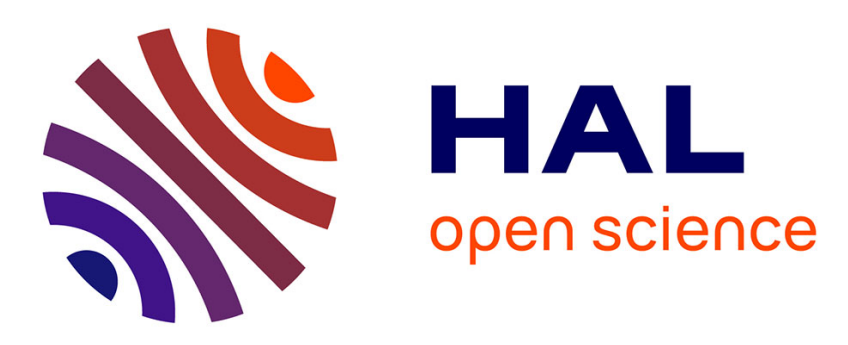

\title{
Intramyocardial transplantation of mesenchymal stromal cells for chronic myocardial ischemia and impaired left ventricular function: Results of the MESAMI 1 pilot trial
}

Damien Guijarro, M Lebrin, Olivier Lairez, Philippe Bourin, Nicolas Piriou, Jean-Luc Pozzo, Gilles Landes, Matthieu Berry, Thierry Le Tourneau, Daniel Cussac, et al.

\section{- To cite this version:}

Damien Guijarro, M Lebrin, Olivier Lairez, Philippe Bourin, Nicolas Piriou, et al.. Intramyocardial transplantation of mesenchymal stromal cells for chronic myocardial ischemia and impaired left ventricular function: Results of the MESAMI 1 pilot trial. International Journal of Cardiology, 2016, 10.1016/j.ijcard.2016.02.016 . inserm-01269644

\section{HAL Id: inserm-01269644 https://www.hal.inserm.fr/inserm-01269644}

Submitted on 5 Feb 2016

HAL is a multi-disciplinary open access archive for the deposit and dissemination of scientific research documents, whether they are published or not. The documents may come from teaching and research institutions in France or abroad, or from public or private research centers.
L'archive ouverte pluridisciplinaire HAL, est destinée au dépôt et à la diffusion de documents scientifiques de niveau recherche, publiés ou non, émanant des établissements d'enseignement et de recherche français ou étrangers, des laboratoires publics ou privés. 


\section{Accepted Manuscript}

Intramyocardial transplantation of mesenchymal stromal cells for chronic myocardial ischemia and impaired left ventricular function: Results of the MESAMI 1 pilot trial

D. Guijarro, M. Lebrin, O. Lairez, P. Bourin, N. Piriou, J. Pozzo, G. Landes, M. Berry, T. Letourneau, D. Cussac, L. Sensebe, F. Gross, G. Lamirault, A. Huynh, A. Manrique, J.B. Ruidavet, M. Elbaz, J.N. Trochu, A. Parini, S. Kramer, M. Galinier, P. Lemarchand, J. Roncalli

PII:

S0167-5273(16)30228-5

DOI: doi: $10.1016 /$ j.ijcard.2016.02.016

Reference: $\quad$ IJCA 21983

To appear in: $\quad$ International Journal of Cardiology

Received date: 21 September 2015

Revised date: $\quad 10$ January 2016

Accepted date: 1 February 2016

Please cite this article as: Guijarro D, Lebrin M, Lairez O, Bourin P, Piriou N, Pozzo J, Landes G, Berry M, Letourneau T, Cussac D, Sensebe L, Gross F, Lamirault G, Huynh A, Manrique A, Ruidavet JB, Elbaz M, Trochu JN, Parini A, Kramer S, Galinier M, Lemarchand P, Roncalli J, Intramyocardial transplantation of mesenchymal stromal cells for chronic myocardial ischemia and impaired left ventricular function: Results of the MESAMI 1 pilot trial, International Journal of Cardiology (2016), doi: 10.1016/j.ijcard.2016.02.016

This is a PDF file of an unedited manuscript that has been accepted for publication. As a service to our customers we are providing this early version of the manuscript. The manuscript will undergo copyediting, typesetting, and review of the resulting proof before it is published in its final form. Please note that during the production process errors may be discovered which could affect the content, and all legal disclaimers that apply to the journal pertain. 
Intramyocardial Transplantation of Mesenchymal Stromal Cells for Chronic Myocardial Ischemia and Impaired Left Ventricular Function: Results of the MESAMI 1 Pilot Trial.

D.GUIJARRO ${ }^{1 *}$, M.LEBRIN $^{2,3^{*}}$, O.LAIREZ ${ }^{2,5}$, P.BOURIN $^{4}$, N.PIRIOU $^{1}$, J. POZZO $^{2,5}$, G.LANDES $^{1}$, M BERRY ${ }^{2}$, T.LETOURNEAU ${ }^{1}$, D.CUSSAC ${ }^{5}$, L.SENSEBE ${ }^{4}$, F.GROSS $^{2,3}$, G.LAMIRAULT $^{1}$, A.HUYNH ${ }^{6}$, A. MANRIQUE ${ }^{7}$, J.B. RUIDAVET ${ }^{8}$, M. ELBAZ $^{2}$, JN.TROCHU ${ }^{1}$, A.PARINI ${ }^{5}$, S. KRAMER $^{9}$, M.GALINIER ${ }^{2}$, P.LEMARCHAND ${ }^{1}$, J.RONCALLI ${ }^{2,3,5}$

${ }^{1}$ INSERM, UMR1087, l'institut du thorax, CNRS, UMR 6291, Université de Nantes, CHU de Nantes, Nantes, F-44000 France

${ }^{2}$ Department of Cardiology, Institute CARDIOMET, PCVM, University of Toulouse, CHU de Toulouse, France

${ }^{3}$ Clinical Center of Investigation of Biotherapy, CIC, CHU Toulouse, France

${ }^{4}$ French Blood Establishment, Midi-Pyrénées, Toulouse, France

${ }^{5}$ INSERM, UMR1048 Institute of Cardiovascular and Metabolic Diseases (I2MC) Toulouse, France

${ }^{6}$ Department of Hematology, CHU de Toulouse, France

${ }^{7}$ Department of Imaging, CYCERON, CHU de Caen, France

${ }^{8}$ Laboratoire d'épidémiologie et santé communautaire, UMR1027, Toulouse, France

${ }^{9}$ Biologics Delivery Systems, Biosense Webster Inc. Johnson-Johnson, USA

* Contributed equally

All authors take responsibility for all aspects of the reliability and freedom from bias of the data presented and their discussed interpretation

Corresponding author:

Professor Jerome RONCALLI

Department of Cardiology A,

University Hospital of Toulouse,

Rangueil Hospital,

1, Avenue Jean Poulhès TSA50032 
31059 Toulouse Cedex9, France

Tel:+33561323334;

Fax:+33561322246;

Email: roncalli.j@chu-toulouse.fr

\section{Acknowledgement of grant support:}

This work was supported in part by two regional grants from the Programme Hospitalier de Recherche Clinique (PHRC 2005 and PHRC 2006) and Region Midi-Pyrénées (APRTT2011, \# 1005166).

\section{Conflict of interest: None}

Key words: Mesenchymal Stromal Cells, chronic myocardial ischemia, transendocardial injections. 


\section{STRUCTURED ABSTRACT}

Background: The MESAMI 1 trial was a bicentric pilot study designed to test the feasibility and safety of intramyocardially injected autologous bone marrow-derived mesenchymal stromal cells (MSCs) for the treatment of ischemic cardiomyopathy.

Methods and Results: The study included 10 patients with chronic myocardial ischemia, left ventricular (LV) ejection fractions (EFs) of $\leq 35 \%$, and reversible perfusion defects who were on stable optimal medical therapy and were not candidates for revascularization. MSCs (mean: $61.5 \times 10^{6}$ cells per patient) were injected into 10-16 viable sites at the border of the LV scar via a NOGA-guided catheter. Both primary endpoints, feasibility (successful harvest, expansion, and injection of autologous MSCs) and safety (absence of severe adverse events [SAEs]) were met in all 10 patients at the 1-month follow-up time point, and none of the SAEs reported during the full 2-year follow-up period were attributable to the study intervention. The results of secondary efficacy endpoint analyses identified significant improvements from baseline to Month 12 in LVEF $(29.4 \pm 2.0 \%$ versus $35.7 \pm 2.5 \%$; $\mathrm{p}=0.003), \mathrm{LV}$ end-systolic volume $(167.8 \pm 18.8 \mathrm{~mL}$ versus $156.1 \pm 28.6 \mathrm{~mL} ; \mathrm{p}=0.04), 6$ minute walk test and NYHA functional class.

Conclusions: Our results suggest that autologous MSCs can be safely administered to the hearts of patients with severe, chronic, reversible myocardial ischemia and impaired cardiac function and may be associated with improvements in cardiac performance, LV remodeling, and patient functional status. A randomized, double blind, multicenter, placebo-controlled clinical trial (MESAMI 2) will evaluate the efficacy of this treatment approach in a larger patient population.

Clinical Trial Registration: Unique identifier: NCT01076920 


\section{INTRODUCTION}

Ischemic cardiomyopathies continue to be among the leading causes of death in western countries, and although many important advances in the treatment of heart failure have evolved during the last decade, most focus only on relieving symptoms and preventing disease progression. Strategies for revascularizing the myocardium and limiting ventricular remodeling must be considered before more invasive interventions are performed, and researchers are currently developing a variety of therapies with stem cells that have been obtained from numerous sources and can provide trophic and paracrine support, or even replace the dying cells. Adult bone marrow-derived mesenchymal stromal cells (MSCs) are a particularly promising cell type, because of their capacity to differentiate into endothelial cells, to participate in the development of new blood vessels in ischemic tissues, and to promote the activity of resident cardiac cells. Preliminary evidence of the efficacy of MSC injection for treatment of acute and chronic myocardial infarction has been observed in both animal models and early clinical trials (1-4), but improvements in symptoms, functional status, or ejection fraction (EF) have not been achieved in recent placebo-controlled clinical trials with bone marrow-derived or adipose tissuederived MSCs $(5,6)$.

The inconsistent results achieved in trials of MSC therapy could be caused by a variety of factors, including variations in the methods used for cell selection, culture, and delivery. Thus, the primary objective of the MESAMI program is to develop a fully standardized regimen for autologous MSC selection, culture, and administration that can serve as a foundation for the industrialization of cell therapy during the next decade. Here, we report the results of the phase-I MESAMI 1 trial, which was designed to provide an initial assessment of the safety and feasibility of autologous MSC therapy in patients with severe chronic myocardial ischemia and impaired cardiac function. 


\section{METHODS}

\section{Study design and patient population}

The bicentric MESAMI trial was a pilot, phase 1, prospective, non-randomized, open-label investigation of the feasibility and safety of autologous MSC administration for the treatment of patients with severe left ventricular dysfunction secondary to coronary artery disease (CAD). The study protocol was approved by the ethics review board of Toulouse 1 CPP (Comité de Protection des Personnes), and the study was conducted in accordance with the Declaration of Helsinki and under an Investigational National Drug Application from the French National Medicines Agency (ANSM: Agence Nationale de Sécurité du Médicament, France). All patients provided written informed consent, and the study is registered at clinicalTrials.gov (registration no. NCT01076920). The study was composed of 4 stages: 1) assessment of a patient's eligibility for inclusion, 2) bone marrow aspiration and MSC isolation/expansion, 3) MSC injection, and 4) the follow-up period, which consisted of five visits. Day 0 was defined as the day of intramyocardial cell delivery. After MSC injection, patients remained in the hospital and were observed for at least 48 hours before discharge (Figure 1).

Patients between 18 and 75 years of age with chronic coronary artery disease (CAD), left ventricular (LV) ejection fractions (EF) of 35\% or less, and either Class II-IV heart failure as defined by the New York Heart Association (NYHA) or Class III-IV angina pectoris as assessed by the Canadian Cardiovascular Society, were eligible for inclusion. Patients also must have had reversible perfusion defects in 2 or more of 17 AHA-defined LV segments (as assessed by single-photon emission computed tomography [SPECT]), no possibility for additional coronary artery bypass surgery or percutaneous coronary intervention (PCI), and an implanted, functional, automated cardiovertor defibrillator (ICD). All patients were required to be on optimal pharmacological therapy, and their medical therapy must have been stable for at least one month before the date of eligibility assessment. 
Patients were excluded if they had undergone revascularization (PCI or coronary artery bypass grafting $[\mathrm{CABG}]$ ) or cardiac resynchronization therapy during the previous 3 months, or if an additional revascularization procedure was planned for within the next 30 days. Patients were also excluded if they had acute coronary syndrome, sustained ventricular arrhythmias, chronic atrial fibrillation, wall thickness in the target region of less than $8 \mathrm{~mm}$ (as determined by two-dimensional echocardiography), LV thrombus, severe peripheral vascular disease that would preclude femoral artery access (determined at the time of the first catheterization procedure), aortic stenosis with valve area of less than $1 \mathrm{~cm}^{2}$ (which would prohibit catheter access to the LV), positive serological test results for human immunodeficiency virus or hepatitis, active uncontrolled infection, a prosthetic aortic valve, current neoplasm, or a history of neoplasm within the last 3 years.

\section{Study endpoints}

The primary endpoints of this investigation were feasibility and safety at the one-month follow-up time point. Feasibility was defined as successful completion of the bone marrow aspiration, cell culture, and percutaneous intramyocardial injection procedures. The safety endpoint was defined as the incidence of treatment-related serious adverse events (SAEs) that occurred during the treatment procedure or during follow-up. SAEs were defined as events leading to hospitalization, death, or persistent or significant disability, including systemic embolism (stroke), major bleeding, and major adverse cardiac events (MACEs) (e.g., non-fatal MI, worsening heart failure, sustained ventricular arrhythmias). SAEs, non-serious adverse events, observations made during physical examinations, and regular vital sign measurements were recorded at each follow-up visit for a total of two years. The occurrence of post-injection arrhythmia was also evaluated at each visit via 12-lead electrocardiogram (ECG) and ICD monitoring.

Secondary endpoints were assessed at baseline (M0) and after 3 months (M3) and 12 months (M12) of follow-up. Secondary endpoints included changes from baseline in LVEF (as assessed by echocardiography), LV end-diastolic volume (LVEDV), LV end-systolic volume (LVESV), twodimensional speckle-tracking echocardiography (2D-STE) longitudinal strain analyses, exercise peak 
oxygen consumption per unit time (peak $\mathrm{VO}_{2}$ ), the 6-minute walk test, NYHA functional classification, and quality of life (Minnesota Living With Heart Failure Questionnaire [MLHFQ]). The 6-minute walk test was performed as recommended by the American Thoracic Society. Perfusion was determined by SPECT imaging and included the summed rest and summed stress perfusion scores (SRS and SSS, respectively), as well as the summed difference score (SDS), which was calculated as the difference between stress and rest perfusion in each LV segment.

\section{MSC isolation and expansion}

Bone marrow aspiration was performed from the iliac crest with local anesthesia; $15-20 \mathrm{~mL}$ of aspirate was collected and immediately transported at room temperature to GMP facilities located at the French Blood Establishment (Etablissement Français du Sang, Midi-Pyrénées and Centre-Atlantique, France). Cell culture was performed according to a protocol that has been approved by both the Graft Group of French Bone Marrow Transplant and Cellular Therapy Society and the ANSM (7). Cell preparations were screened for human immunodeficiency virus types 1 and 2, syphilis, human T-lymphotropic virus type 1 and 2, and hepatitis B and C. Preparations that were positive for syphilis remained eligible for the trial, but preparations that were positive for any of the other screening tests were excluded.

Total duration of the cell-culture protocol was $17 \pm 1$ days, and the initial cell density was $5 \times 10^{4}$ cells $/ \mathrm{cm}^{2}$. Cells were cultured at $37^{\circ} \mathrm{C}$ and $5 \% \mathrm{CO}_{2}$ in flasks (Cellstack, MACOPHARMA) with medium containing $\alpha$-minimal essential medium ( $\alpha$-MEM) or Dulbecco's modified Eagle's medium supplemented with $10 \%$ fetal calf serum, $1 \mathrm{ng} / \mathrm{mL}$ fibroblast growth factor 2 (both GMP grade) and antibiotics. Non-adherent cells were removed after 48 to 72 hours (during the first change of medium) and the medium was subsequently changed twice per week; bacteriological analysis (aerobic and anaerobic blood culture) was performed on the supernatant collected during the last medium change. After 17 days of culture, the cells were washed with phosphate buffered saline (PBS), detached with trypsin, and counted, and their phenotype was analysed via flow cytometry for the expression of CD45, CD14, CD73, CD90, and CD13; then, the cells were washed three times in PBS without $\mathrm{Ca}^{++}$ and $\mathrm{Mg}^{++}$and resuspended in a solution of human albumin (4\%) at a concentration of $20 \times 10^{6}$ 
cells/mL. Cell viability was assessed via the trypan-blue exclusion method. Bacteriological analyses were performed, and the expression of human telomerase reverse transcriptase was evaluated, but the result was not a liberator test. Preparations that contained more than $30 \times 10^{6}$ to $60 \times 10^{6}$ cells, with $>75 \%$ viability, $<6 \%$ CD45 and CD14 expression, and >80\% CD90, CD13, and CD73 expression were approved for administration to study patients.

\section{Cell delivery}

MSCs were transendocardially administered via the NOGA XP system and an 8-F Myostar mappinginjection catheter (Biologics Delivery Systems Group, Johnson \& Johnson, Irwindale, CA). Each patient received 10 to $16(200-\mu \mathrm{L})$ injections (total volume $2000-3200 \mu \mathrm{L})$ in regions of viable, dysfunctional myocardium, which were identified via electromechanical mapping and defined by a univoltage potential of $4 \mathrm{mV}$ or greater and reduced longitudinal linear shortening. Trans-thoracic echocardiograms were obtained for each patient immediately after cell injection and again before patient discharge and examined for evidence of pericardial effusion.

\section{Cardiac imaging}

Measurements were performed blinded at two independent core-imaging laboratories: the SPECT core Lab (A. Manrique, N. Piriou, D. Guijarro), and the echo core lab (Th. Le Tourneau).

\section{SPECT imaging}

Stress SPECT imaging was performed (8) under effort- and/or adenosine-induced stress $(0.14 \mathrm{mg} / \mathrm{kg}$ per min for 6 minutes) at baseline, 3 months, and 12 months after cell injection. Thallium-201 was injected 3-5 minutes after adenosine infusion or immediately after effort-induced stress. Resting images were obtained after a second injection of Thallium-20130 minutes later. Reconstructed images yielded long and short-axis projections oriented perpendicular to the heart's axis; short-axis slices were displayed in polar map format and adjusted for peak myocardial activity (100\%). The myocardium was divided into 17 segments as recommended by the AHA/American College of Cardiology (9). Myocardial perfusion was analyzed with Quantitative Gated SPECT software 
(Cedars-Sinai Medical Center, Los Angeles, California), and segment tracer activity was categorized on a 5-point scale according to the following criteria: 0 , normal perfusion with tracer activity between $80 \%$ and $100 \% ; 1$, tracer activity between $70 \%$ and $79 \% ; 2$, tracer activity between $50 \%$ and $69 \% ; 3$, tracer activity between $20 \%$ and $49 \%$; and 4, tracer activity of less than $19 \%$. Perfusion defects were considered present whenever tracer activity was less than $79 \%$ of maximum. Segmental scores while the patient was under stress were summed to calculate the patient's summed stress score (SSS), segmental scores while the patient was at rest were summed to calculate the summed rest score (SRS), and the summed difference score (SDS) was calculated as the difference between the SSS and the SRS.

Thallium-201 SPECT imaging was performed at baseline, 3 months, and 12 months after cell injection via a rest-redistribution protocol and by using a standard camera to assess myocardial viability. The LV was divided into 17 segments as defined by the AHA for all analyses (8), and the activity of each LV segment was expressed as the mean activity of all pixels in the segment divided by the highest pixel activity observed in the myocardium. Each segment was defined as viable (uptake $\geq 50 \%$ ) or nonviable (uptake $<50 \%$ ).

\section{Transthoracic echocardiography}

Transthoracic echocardiography was performed via a standard protocol and with a Vivid E9 Dimension system (Vingmed, General Electric, Milwaukee, WI, USA); all recordings were stored digitally for offline analysis. Images were recorded prospectively and analyzed at the core echo laboratory in a blinded fashion. LV volumes and LVEF were calculated via the Simpson's biplane method in apical four- and two-chamber views.

\section{Two-dimensional speckle-tracking echocardiography (2D-STE)}

2D-STE longitudinal strain analyses were performed with high-frame-rate (60-90 frames/s), gray-scale images in the conventional apical 4-, 3-, and 2-chamber views (10). The endocardial border was manually traced at end-systole, and the software automatically traced the region of interest within the 
myocardium. The integrity of speckle tracking was detected automatically and visually evaluated; if the tracking was poor, the tracing for the region of interest was manually adjusted. Segments with persistently inadequate tracking and studies with two or more segments inadequately tracked were excluded from analysis. Longitudinal strain was calculated as the change in length divided by the original length of the speckle pattern over the cardiac cycle and expressed as a percentage; myocardial longitudinal lengthening was represented as positive strain and myocardial longitudinal shortening was represented as negative strain (10). Peak systolic longitudinal strain was automatically displayed as a 17-segment polar map, which included the strain values for each segment and a mean global longitudinal strain (GLS) value for the entire LV. Overall, segmental analyses were performed by matching NOGA, SPECT, and echo images with the bull-eye technique and then correlating the segments to define the injected and non-injected segments.

\section{Statistical analysis}

Data are presented as mean \pm standard error of the mean for quantitative variables and as percentages for categorical variables. Data collected for the same patient at different time points were evaluated as repeated measures data, and the trend of the response over time was fit via linear mixed effects models. Random intercept and random slope models were used to accommodate heterogeneity in the intercepts and slopes for each individual patient's regression line. Mixed models were adjusted for age, sex, and cardiology departments. When the results of the mixed model test were significant, the Wilcoxon signed-rank test was used for post-hoc pairwise analysis, and false discovery rate control was used to correct for multiple comparisons. Testing was two-tailed, and the level of significance was set at $\mathrm{p} \leq 0.05$. Statistical analyses were performed using SAS statistical software, release 9.4 (SAS Institute Inc, Cary, North Carolina, U.S.A.). 


\section{RESULTS}

The patient follow-up period began at the time of cell administration. Safety and clinical outcomes were evaluated from data collected over a 2-year follow-up period, while cardiac function and quality of life were evaluated from data collected during the first year of follow-up.

\section{Patient demographics and distribution}

A total of 10 patients from the University Hospitals of Toulouse and Nantes were enrolled in the MESAMI 1 study from December 2009 to January 2012. All patients had persistent myocardial ischemia in 2 or more of 17 LV segments (assessed via Thallium-201 SPECT imaging) and a medical history with at least one myocardial infarction. Mean duration of CAD was $9.5 \pm 2.4$ years, and nine patients had more than one affected vessel. Seven patients had undergone either PCI or CABG. All patients participated in each of the 4 stages of the study (eligibility assessments, bone marrow aspiration and MSC isolation/expansion, MSC injection, and follow-up). None of the patients withdrew consent and all completed the full two-year follow-up period.

\section{Characterization of the cell therapy product}

After expansion, cell viability measurements approached $95 \%$ in each preparation; CD73, CD90, and CD13 were each expressed by more than $98 \%$ of cells, and less than $1 \%$ of cells expressed CD45 or CD14 (Table 2). The results from karyotype analyses were normal, and there were no reports of cell contamination or other safety concerns.

\section{Primary endpoint analysis: feasibility and safety one month after cell injection}

Both primary endpoints, feasibility (i.e., successful completion of the bone marrow aspiration, cell culture, and percutaneous intramyocardial injection procedures) and safety (i.e., absence of SAEs) at the one-month time point, were met in all patients $(n=10)$. Bone marrow aspirates $(16.8 \pm 0.6 \mathrm{~mL})$ were obtained from each patient without complications and with no need for post-operative analgesia. MSCs were successfully isolated from all bone-marrow samples and expanded, and each patient was 
successfully administered a total of $40 \times 10^{6}$ to $100 \times 10^{6}$ (mean: $61.5 \pm 7.0 \times 10^{6}$ ) MSCs via intramyocardial injections at 10 to 16 locations (mean: $13.7 \pm 0.5$ ). The injections were performed without complications and were well tolerated with no allergic or local inflammatory reactions, no injection-related toxicities or subsequent toxicities that were attributable to the MSC injection, no incidents of infection or pericardial effusion, and no sign of tumor development. No SAEs were reported: there were no incidents of re-hospitalization, stroke, bleeding, or MACEs, and no deaths. Two patients each had one adverse event during the injection procedure: one patient experienced a vasovagal reaction caused by arterial puncture, and one patient experienced non-sustained ventricular tachycardia that resolved spontaneously and was not attributable to the cell therapy product. The tachycardia was caused by mobilization of the catheter into the LV and occurred in a patient whose medical history included ventricular arrhythmia.

\section{Two-year safety assessment}

Eleven SAEs were reported during the full two-year follow-up period (Table 3), none of which were related to the study intervention or the cell therapy product (as determined via Data Safety Monitoring Board review). Only one SAE occurred during the first year of follow-up, and it was attributable to the development of a new condition that required nasal surgery. Of the ten SAEs that occurred during the second year of follow-up, six (four of which occurred in the same patient) were attributable to progression of the pre-existing ischemic heart failure, and the other four were attributable to the progression of another pre-existing condition (diabetes, renal failure, anaemia, or peripheral arterial disease).

\section{Secondary endpoints (efficacy)}

\section{Echocardiographic assessments of LV function}

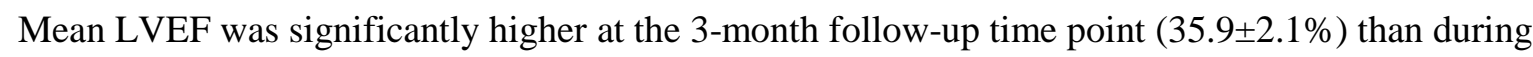
baseline assessments performed before cell administration $(29.4 \pm 2.0 \% ; \mathrm{p}<0.01, \mathrm{n}=10)$, and the improvement was maintained at the 1 -year follow-up time point $(35.7 \pm 2.5 \%$; $p<0.01$ versus baseline, $\mathrm{n}=10$ ) (Figure 2A). Mean LVESV also improved from baseline $(167.8 \pm 18.8 \mathrm{~mL})$ to Month 3 
$(151.9 \pm 17.7 \mathrm{~mL})$, and the improvement achieved significance by Month $12(156.1 \pm 28.6 \mathrm{~mL} ; \mathrm{p}=0.04$ versus baseline) (Figure 2B). Mean LVEDV was similar at all three time points (baseline: $232.2 \pm 19.8$ mL, Month 3: 235.3 $\pm 20.6 \mathrm{~mL}$, Month 12: 232.3 \pm 29.3 ; $\mathrm{p}=0.31$ ).

\section{$\underline{2 D-S T E}$ assessments of segmental contraction}

Assessments of the wall motion score index (WMSI) for the entire LV ( $\mathrm{p}=0.917)$, the global longitudinal strain (GLS) ( $\mathrm{p}=0.09)$, and the mean longitudinal strain scores (i.e., the extent of contraction in the longitudinal direction, expressed as a percentage) (Figures 2C-D) for control segments of the LV that were not injected with MSCs $(-5.5 \pm 6.9$ at M0 to $-7.2 \pm 9.5$ at M3 and $-7.8 \pm 6.9$ at M12; $\mathrm{p}=0.157$ ) did not change significantly over time; however, the extent of contraction increased significantly from baseline $(-2.1 \pm 6.3 \%)$ to Month $3(-7.3 \pm 5.8 \%$; $p<0.05)$ in segments that received cell injections, and this significant improvement was maintained at Month $12(-5.5 \pm 5.4 \% ; \mathrm{p}<0.05$ versus baseline).

\section{SPECT assessments of myocardial ischemia and viability}

Summed stress scores were significantly lower (signaling a decline in myocardial ischemia) at Month $3(25.3 \pm 3.9)$ than at baseline (34.1 $\pm 0.6 ; \mathrm{p}=0.031)$ (Figure 3A); SSS was also lower at Month 12 than at baseline, but not significantly ( $\mathrm{p}=0.05$ ), and neither SDS or SRS changed significantly from baseline to Month 3 or from baseline to Month 12 (Figure 3B and 3C). Qualitative analyses of the number of non-ischemic myocardial segments $(\mathrm{p}=0.07)$, the number of segments with reversible ischemia $(\mathrm{p}=0.44)$, and the number of segments with non-reversible ischemia $(\mathrm{p}=0.09)$ were also unchanged throughout the 12-month follow-up period. Myocardial viability assessments and the number of viable segments did not change significantly $(\mathrm{p}=0.234)$ from baseline $(14.6 \pm 3)$ to Month $3(13.8 \pm 3)$ or Month $12(12.7 \pm 3)$.

\section{Functional status and quality of life}

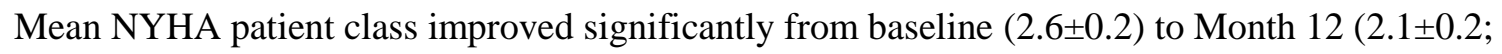
$\mathrm{p}<0.05)$; the proportion of patients in Class I increased from $0 \%$ at baseline to $10 \%(\mathrm{n}=1)$ at Month 3 
and to $20 \%(\mathrm{n}=2)$ at Month 12, while the proportion in Class III declined by half, from $60 \%(\mathrm{n}=6)$ at baseline to 30\% (n=3) at Month 12 (Figure 4). Quality of life scores (MLHFQ) improved significantly from baseline to Month $3(\mathrm{p}<0.05)$, but not from baseline to Month 12, while measurements of exercise peak oxygen consumption tended to improve over time $\left(\mathrm{VO}_{2}[\mathrm{~mL} / \mathrm{min}\right.$ per $\mathrm{kg}]$, baseline: 12.6 \pm 1.3 , Month 3: 13.2 \pm 1.8 , Month 12: 14.1 $\pm 1.7, \mathrm{p}=0.62$ ), and the trend for the 6-minute walk test was significant (baseline: $354.6 \pm 25.5 \mathrm{~m}$, Month 3: $360.2 \pm 32.4 \mathrm{~m}$, Month 12: $376.1 \pm 26.7 \mathrm{~m}$; $\mathrm{p}=0.05$ ). Changes to the patients' drug treatment regimens were minor and not significant (Table 4); betablocker use increased in 2 patients (carvedilol: from $18.75 \mathrm{mg}$ to $37.5 \mathrm{mg}$; bisoprolol from $7.5 \mathrm{mg}$ to $10 \mathrm{mg}$ ), the dose of angiotensin-converting enzyme (ACE) inhibitors increased in 1 patient (ramipril: from $5 \mathrm{mg}$ to $7.5 \mathrm{mg}$ ), and loop-diuretic use declined in 1 patient (furosemide: from $200 \mathrm{mg}$ to $12 \mathrm{mg}$ ). 


\section{DISCUSSION}

The results from our MESAMI 1 trial suggest that autologous MSCs can be safely and feasibly harvested, expanded, and transendocardially injected (via a NOGA-guided catheter) into the hearts of patients with severe, chronic, reversible myocardial ischemia and impaired cardiac function, and that this treatment approach may be associated with improvements in myocardial performance and patient functional status. All four stages of the protocol were successfully completed for each of the 10 enrolled patients: MSC harvest was accomplished without complications and with no need for postoperative analgesia, the expansion protocol yielded $85.3 \pm 11.3 \times 10^{6}$ cells per patient $(\sim 95 \%$ of which were viable), and the injection procedure was well tolerated with no allergic or local inflammatory reactions, no injection-related toxicities, and no SAEs. Eleven SAEs were reported during the twoyear follow-up period, but none of them were related to the study intervention, and significant improvements in echocardiographic assessments of LVEF and/or LVESV were observed at Month 3 (LVEF) and/or Month 12 (LVEF and LVESV) after cell administration. Patients' NYHA functional class and 6-minute walk test also improved significantly during the 12-month follow-up period, while clinical assessments of patient function $\left(\mathrm{VO}_{2}\right)$ and quality of life (MLHFQ) tended to improve over time, but not significantly.

The safety of MSC injection in patients with chronic ischemic cardiomyopathy is also supported by results from the TAC-HFT trial (5), a randomized, controlled study that included 19 patients who were treated with injected MSCs and 10 who received injections of placebo. However, the inclusion criteria for our MESAMI 1 study (e.g., LVEF $<35 \%$ and reversible ischemia in two or more of the 17 AHAdefined LV segments) selected for patients in whom the extent of cardiac dysfunction was considerably more severe. For example, $60 \%$ of patients in our study were NYHA Class III, compared to $10.5 \%$ of patients who were administered MSCs in the TAC-HFT trial, and mean LVEF at baseline

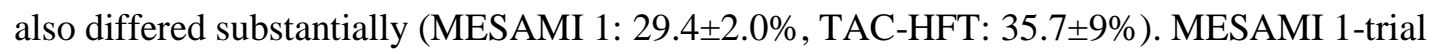
participants were also more severely compromised than patients in either of two randomized, controlled studies that investigated the use of injected bone marrow mononuclear cells for the 
treatment of myocardial disease: the FOCUS-CCTRN trial (11), which was open to patients with chronic CAD whose LVEF was as high as $45 \%$, and a study reported by van Ramshorst et al. (12), which included patients with refractory angina pectoris whose mean baseline LVEF was $56 \pm 12 \%$ in the cell-treatment group. Thus, the results reported here suggest that autologous MSC injection may be safe, even for patients whose myocardial disease is particularly advanced.

The improvements in LVEF reported here were not associated with MSC injection in the TAC-HFT trial (5). This apparent discrepancy may have evolved from our use of the NOGA catheter, which (unlike the system used in the TAC-HFT trial) enabled us to evaluate the viability and extent of myocardial dysfunction for each injection site electromechanically at the time of cell administration. Scar size was significantly improved in MSC-treated patients from the TAC-HFT study but could not be evaluated here, because the study participants had an ICD, as recommended by the 2010 ESC guidelines for patients whose LVEF is $\leq 35 \%$ (13). Whether the observed improvement in scar size reported in the TAC-HFT trial evolved from a decline in fibrosis, rather than an increase in the thickness of the myocardium, has yet to be determined. Furthermore, the $6.5 \%$ improvement in LVEF observed in our MESAMI 1 patients is very similar to the $6.2 \%$ increase reported for the MSC therapy group in the recently published MSC-HF trial (6.2\%) (14), and although bone marrow mononuclear cells (rather than MSCs) were associated with significant improvements in LVEF after administration to patients in the FOCUS-CCTRN trial, changes in LVESV, maximum oxygen consumption, and the occurrence of MACE were not significant (11). MSCs also display trophic properties and secrete paracrine factors associated with improvements in apoptosis, inflammation, angiogenesis, and fibrosis (15), which suggests that they may be more effective than BMCs for the treatment of myocardial disease, particularly in patients with heart failure.

The improvements in LVEF observed in patients from the MESAMI 1 trial were matched by significant increases in longitudinal strain measurements and accompanied by significant declines in SSS at Month 3. This observation is encouraging, because SSS is an independent predictor of adverse cardiac events in patients with a history of previous myocardial infarction (16); however, significant 
declines were not maintained in SSS measurements at Month 12, which suggests that the progression of ischemic myocardial disease may not be halted by a single treatment with MSC therapy. Thus, patients may require a series of treatments administered over an extended period to obtain maximal benefit, but the studies required to develop such an approach have yet to be initiated.

The layers of muscle fibers in the heart are aligned in multiple orientations (17) and produce a pattern of structural changes (i.e., the deformation profile) as the LV contracts that includes twists, rotations, and shortening of the myocardial wall (18). Thus, movements within the myocardial wall are difficult to monitor via Tissue Doppler Imaging, because the technique requires sufficient alignment between the ultrasound beam and the direction of motion. 2D-STE assessments are free of these alignment issues, because they track the movement of minute regions of the myocardium, each of which can be identified by a unique and relatively stable pattern of "speckles," and the value of this technique for characterizing myocardial contractile activity has been demonstrated in a number of studies.

Longitudinal myocardial deformation analyses can provide strong prognostic information in patients with heart failure (23), and specific characteristics associated with the deformation profile can be used to detect the presence of clinical conditions that cannot be identified via conventional kinetic analyses, such as WMSI (19-22). Peak systolic longitudinal strain measurements also correlate well with infarct mass over a wide range of infarct sizes and locations, and segmental analyses are capable of identifying the relationship between the severity of contractile dysfunction and the amount of scar tissue in each segment (24). Roes, et al. (25) found that in a population of 90 patients with chronic ischemic LV dysfunction, mean strain was $-10.4 \pm 5.2 \%$ in segments without scar tissue versus $0.6 \pm 4.9 \%$ in segments with transmural scars, and that a strain of $-4.5 \%$ differentiated between viable and scarred segments with $81.2 \%$ sensitivity and $81.6 \%$ specificity. Thus, although measurements of WMSI and global longitudinal strain were unchanged in our MESAMI 1 trial, the significant improvements observed in cell-treated segments (from $-2.1 \pm 6.3 \%$ at $\mathrm{M} 0$ to $-7.3 \% \pm 5.8$ at $\mathrm{M} 3$ and 5.5 $\pm 5.4 \%$ and M12; $\mathrm{p}=0.0005)$, but not in untreated segments, strongly suggests that the injected cells improved myocardial viability. These results emphasize the importance of identifying and targeting specific regions of the myocardium for cell delivery (e.g., by using the 3D-NOGA system) and may be 
particularly informative, because comparisons between individual segments are unlikely to be confounded by changes in the patient's drug regimen or medical care.

\section{Study limitations}

We acknowledge that our MESAMI 1 trial was conducted with a very small number of patients $(n=10)$ and did not include a placebo group. Although the outcome appears to be positive, it is difficult to reach meaningful conclusions. Thus, our results must be interpreted with appropriate caution and used primarily for the development of new hypotheses that can be evaluated in subsequent trials.

\section{Perspectives}

The MESAMI 1 trial is part of the feasibility and safety phase of the ongoing MESAMI program, which is dedicated to establishing the use of MSCs as an advanced-therapy medicinal product (ATMP), and to obtaining Marketing Authorization for MSCs in the European Union through the $1^{\text {st }}$ Cell Therapy European Platform (Cell For Cure, Les Ullis, France). According to European regulations, the designation of MSCs as an ATMP requires the use of production processes that meet the guidelines of Good Manufacturing Practices (GMP). Meeting the GMP standard is a worldwide industrial challenge for the production of any cell-therapy product, including MSCs, which are among the most promising tools for cell-based regenerative medicine. The success of the MESAMI program will lead to the development of a mastered production process with relevant and reproducible controls that will ensure the efficient production of a well-defined, safe, high-quality, and effective MSC product. Production of mesenchymal stromal cells according to good manufacturing practices has been previously and extremely detailed by our group (7). The efficiency of our current production process is now being tested in a larger patient population via a randomized, double-blind, multicenter, placebocontrolled clinical study (the MESAMI 2 trial Clinical Trial Registration: Unique identifier: NCT02462330).

\section{CONCLUSION}


Our results suggest that autologous MSCs can be safely administered to the hearts of patients with severe, chronic, reversible myocardial ischemia and impaired cardiac function and may be associated with improvements in cardiac performance, LV remodeling, and patient functional status.

\section{ACKNOWLEDGMENTS}

The authors would like to thank W. Kevin Cukier-Meisner, PhD, ELS, for his editorial assistance with this manuscript. The authors gratefully thank research technicians involved in the study. 


\section{REFERENCES}

1. Dai W, Hale SL, Martin BJ, et al. Allogeneic mesenchymal stem cell transplantation in postinfarcted rat myocardium: short- and long-term effects. Circulation. 2005; 112:214-23.

2. Gnecchi M, He H, Liang OD, et al. Paracrine action accounts for marked protection of ischemic heart by Akt-modified mesenchymal stem cells. Nat Med. 2005; 11:367-8.

3. Shake JG, Gruber PJ, Baumgartner WA, et al. Mesenchymal stem cell implantation in a swine myocardial infarct model: engraftment and functional effects. Ann Thoracic Surgery. 2002; 73:1919-25.

4. Hare JM, Fishman JE, Gerstenblith G, et al Comparison of allogeneic vs autologous bone marrow-derived mesenchymal stem cells delivered by transendocardial injection in patients with ischemic cardiomyopathy: the POSEIDON randomized trial. JAMA. 2012; 308:2369-79.

5. Heldman AW, DiFede DL, Fishman JE, et al. Transendocardial mesenchymal stem cells and mononuclear bone marrow cells for ischemic cardiomyopathy: the TAC-HFT randomized trial. JAMA. 2014; 311:62-73.

6. Perin EC, Sanz-Ruiz R, Sánchez PL, et al. Adipose-derived regenerative cells in patients with ischemic cardiomyopathy: The PRECISE Trial. Am Heart J. 2014; 168:88-95 e2.

7. Sensebe L, Gadelorge M, Fleury-Cappellesso S. Production of mesenchymal stromal/stem cells according to good manufacturing practices: a review. Stem Cell Res Therapy. 2013; 4:66.

8. Cerqueira MD, Weissman NJ, Dilsizian V, et al. Standardized myocardial segmentation and nomenclature for tomographic imaging of the heart: a statement for healthcare professionals from the Cardiac Imaging Committee of the Council on Clinical Cardiology of the American Heart Association. Circulation. 2002; 105:539-42.

9. van der Geest RJ, Buller VG, Jansen E, et al. Comparison between manual and semiautomated analysis of left ventricular volume parameters from short-axis MR images. Journal Comput Assist Tomogr. 1997; 21:756-65. 
10. Gorcsan J 3rd, Tanaka H. Echocardiographic assessment of myocardial strain. J Am Coll Cardiol. 2011; 58:1401-13.

11. Perin EC, Willerson JT, Pepine CJ, et al. Effect of transendocardial delivery of autologous bone marrow mononuclear cells on functional capacity, left ventricular function, and perfusion in chronic heart failure: the FOCUS-CCTRN trial. JAMA. 2012; 307:1717-26.

12. van Ramshorst J, Bax JJ, Beeres SL, et al. Intramyocardial bone marrow cell injection for chronic myocardial ischemia: a randomized controlled trial. JAMA. 2009; 301:1997-2004.

13. Dickstein K, Vardas PE, Auricchio A, et al. 2010 Focused Update of ESC Guidelines on device therapy in heart failure: an update of the 2008 ESC Guidelines for the diagnosis and treatment of acute and chronic heart failure and the 2007 ESC guidelines for cardiac and resynchronization therapy. Developed with the special contribution of the Heart Failure Association and the European Heart Rhythm Association. Eur Heart J. 2010; 31:2677-87.

14. Mathiasen AB, Qayyum AA, Jørgensen E, et al. Bone marrow-derived mesenchymal stromal cell treatment in patients with severe ischaemic heart failure: a randomized placebo-controlled trial (MSC-HF trial). Eur Heart J;doi.org/10.1093/eurheartj/ehv136 Published online ahead of print 29 April 2015.

15. Mias C, Lairez O, Trouche E, et al. Mesenchymal stem cells promote matrix metalloproteinase secretion by cardiac fibroblasts and reduce cardiac ventricular fibrosis after myocardial infarction. Stem cells. 2009; 27:2734-43.

16. Leslie WD, Tully SA, Yogendran MS, Ward LM, Nour KA, Metge CJ. Prognostic value of automated quantification of 99mTc-sestamibi myocardial perfusion imaging. J Nucl Med. $2005 ; 46: 204-11$.

17. Greenbaum RA, Ho SY, Gibson DG, Becker AE, Anderson RH. Left ventricular fibre architecture in man. Br Heart J 1981;45:248-263.

18. Biswas M, Sudhakar S, Nanda NC et al. Two- and three-dimensional speckle tracking echocardiography: clinical applications and future directions. Echocardiography 2013;30:88105. 
19. Richand V, Lafitte S, Reant P, et al. An ultrasound speckle tracking (two-dimensional strain) analysis of myocardial deformation in professional soccer players compared with healthy subjects and hypertrophic cardiomyopathy. Am J Cardiol 2007;100:128-132.

20. Wang J, Khoury DS, Yue Y, Torre-Amione G, Nagueh SF. Preserved left ventricular twist and circumferential deformation, but depressed longitudinal and radial deformation in patients with diastolic heart failure. Eur Heart J 2008:29:1283-1289.

21. Koyama J, Falk RH. Prognostic significance of strain Doppler imaging in light-chain amyloidosis. JACC Cardiovasc Imaging 2010;3:333-342.

22. Choi JO, Cho SW, Song YB, et al. Longitudinal 2D strain at rest predicts the presence of left main and three vessel coronary artery disease in patients without regional wall motion abnormality. Eur J Echocardiogr 2009;10:695-701.

23. Nahum J, Bensaid A, Dussault C, et al. Impact of longitudinal myocardial deformation on the prognosis of chronic heart failure patients. Circ Cardiovasc Imaging 2010;3:249-256.

24. Gjesdal O, Hopp E, Vartdal T, et al. Global longitudinal strain measured by two-dimensional speckle tracking echocardiography is closely related to myocardial infarct size in chronic ischaemic heart disease. Clin Sci (Lond) 2007;113:287-296.

25. Roes SD, Mollema SA, Lamb HJ, van der Wall EE, de Roos A, Bax JJ. Validation of echocardiographic two-dimensional speckle tracking longitudinal strain imaging for viability assessment in patients with chronic ischemic left ventricular dysfunction and comparison with contrast-enhanced magnetic resonance imaging. Am J Cardiol 2009;104:312-317. 


\section{FIGURE LEGENDS}

Figure 1. MESAMI 1 Trial Flow Diagram (n=10).

\section{Figure 2. Assessments of myocardial function and remodeling.}

(A) Echocardiographic assessments of left-ventricular (LV) ejection fractions and (B) LV end-systolic and end-diastolic volumes (LVESV and LVEDV, respectively) were performed before cell administration (M0) and 3 months (M3) and 12 months (M12) afterward (N=10). (C-D) Twodimensional speckle-tracking echocardiography was performed at M0, M3, and M12 to evaluate the longitudinal strain (i.e., the extent of contraction in the longitudinal direction) in (C) sections from the ischemic region of the LV that had been treated with injected MSCs and in (D) untreated regions of the LV $(\mathrm{N}=4)$. Strain was calculated as (length after contraction - length before contraction)/(length before contraction) and expressed as a percentage. ${ }^{* *} \mathrm{p} \leq 0.01,{ }^{*} \mathrm{p} \leq 0.05$, ns: not significant.

\section{Figure 3. Assessments of myocardial perfusion.}

Single-photon emission computed tomography assessments of (A) the summed stress score (SSS), (B) the summed rest score (SRS), and (C) the summed difference score (SDS) were performed before cell administration (M0, n=10) and 3 months $(M 3, n=10)$ and 12 months $(M 12, n=10)$ afterward. Data for each individual patient are traced with a thin black line and represent the mean of the values obtained for each of the 17 AHA-defined segments of the left ventricle (SEMs have been omitted for visual clarity). Data for the means \pm SEMs for all available patients at each time point are traced with a heavy black line. ${ }^{*} \mathrm{p} \leq 0.05$, ns: not significant.

\section{Figure 4. Assessment of New York Heart Association functional class.}

Evaluations were performed before cell administration (M0) and 3 months (M3) and 12 months (M12) afterward. Data are presented as the percentage of patients in each functional category. ${ }^{*} \mathrm{p}<0.05$, ns: not significant $(\mathrm{N}=10)$. 
Figure 1.

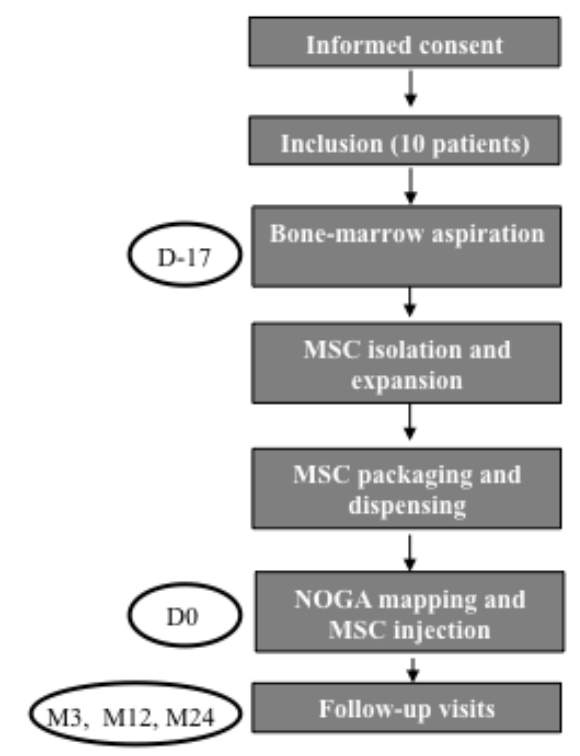


Figure 2.

A
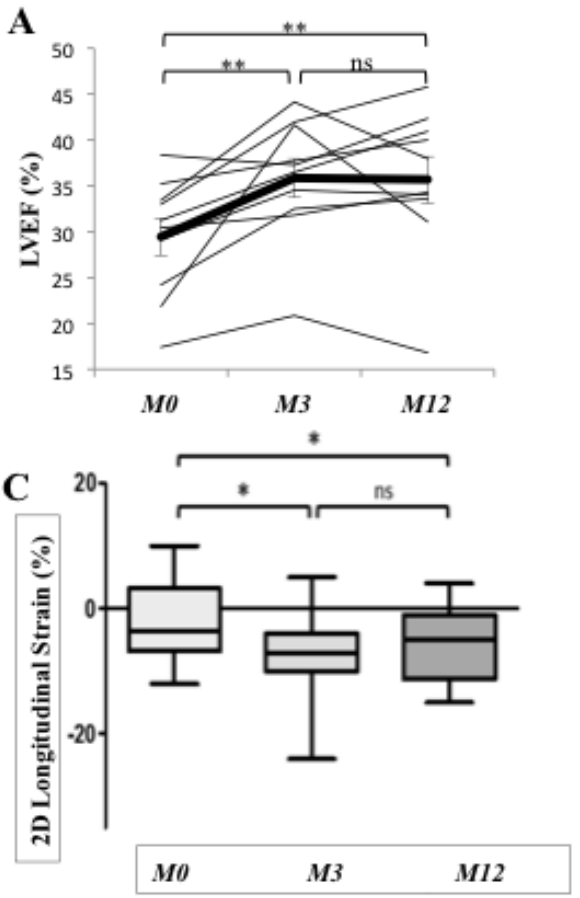
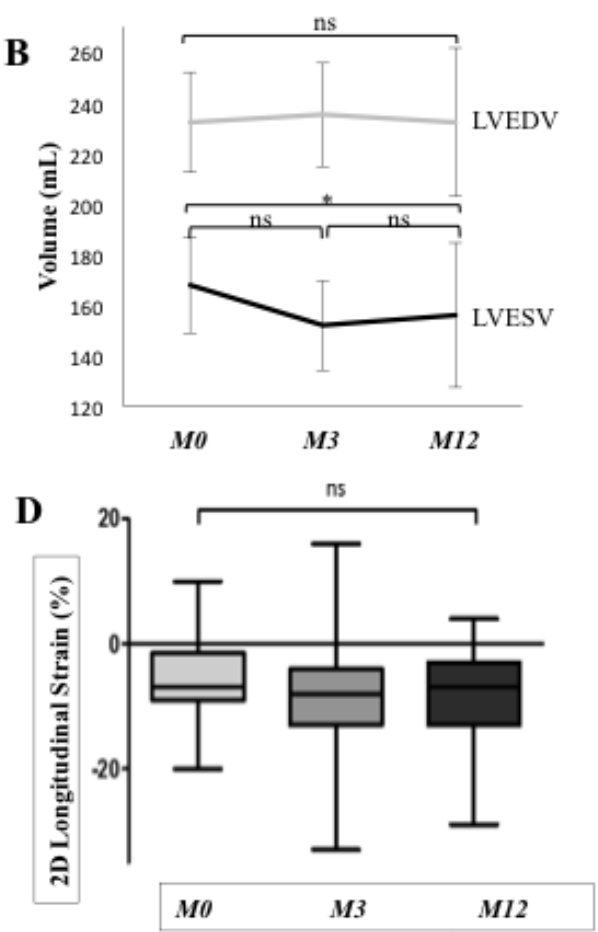
Figure 3.

A

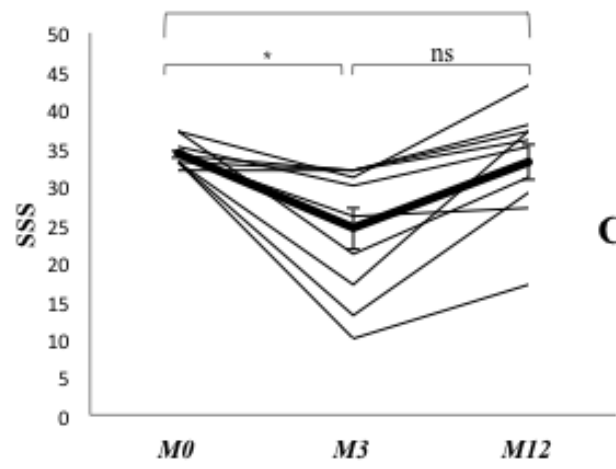

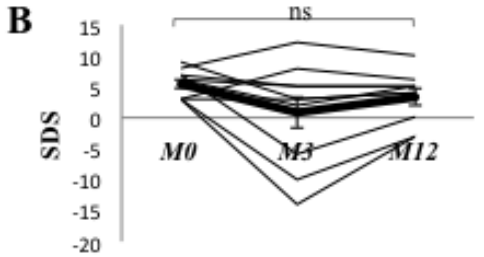

C

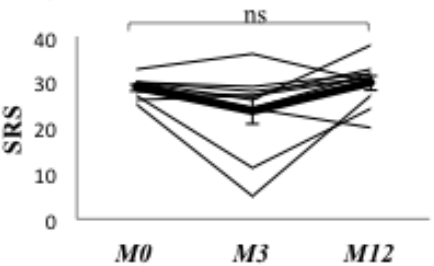


Figure 4.

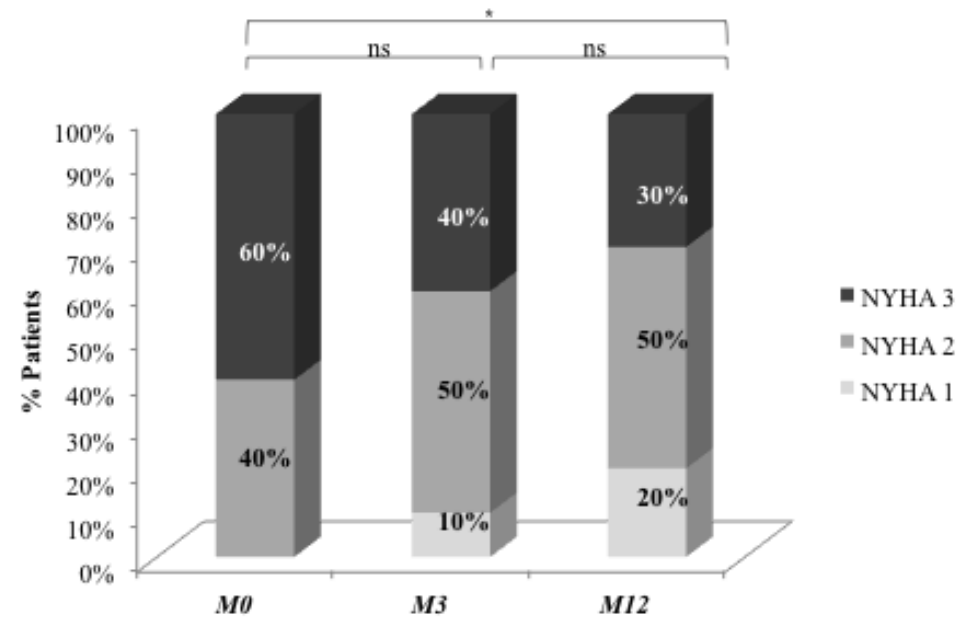


Table 1. Baseline Characteristics

Sex, number of men $(\%)$

Age, years, mean \pm SEM

BMI, $\mathrm{kg} / \mathrm{m}^{2}$, mean $\pm \mathrm{SEM}$

Systolic blood pressure, $\mathrm{mmHg}$, mean \pm SEM

Diastolic blood pressure, $\mathrm{mmHg}$, mean \pm SEM

Resting heart rate, bpm, mean \pm SEM

Duration of disease, years, mean \pm SEM

CCS functional class, mean \pm SEM

NYHA functional class, mean \pm SEM
$9(90)$

$57.2 \pm 1.8$

$29.5 \pm 1.5$

$121 \pm 4$

$72 \pm 2$

$70 \pm 4$

$9.5 \pm 2.4$

$1.8 \pm 0.5$

$2.6 \pm 0.2$

n $(\%)$

$9(90)$

$4(40)$

7 (70)

$5(50)$

2 (20)

$5(50)$

n (\%)

4 (40)

3 (30)

$10(100)$

7(70)

$10(100)$

$6(60)$ 


\begin{tabular}{lc}
\hline 2-vessels & $3(30)$ \\
1 -vessel & $1(10)$ \\
PCI & $6(60)$ \\
CABG & $1(10)$ \\
& $\mathbf{n}(\boldsymbol{\%})$ \\
Medications at time of randomization & $10(100)$ \\
ACE or ARB & $10(100)$ \\
Beta-blockers & $10(100)$ \\
Diuretics (furosemide, mineralo-corticoide) & $10(100)$ \\
Statins & $5(50)$ \\
Nitrates &
\end{tabular}

BMI: body mass index, CCS: Canadian Cardiovascular Society, NYHA: New York Heart Association, PCI: percutaneous coronary intervention, CABG: coronary artery bypass graft, ACE: angiotensin converting enzyme, ARB: angiotensin II receptor blocker. 
Table 2. Characteristics of the cell therapy product

\section{Characteristic}

Total number of

mesenchymal stromal cells $\left(\times 10^{6}\right)$

Viability of cells (\%)

Surface Markers

CD45 (\%)

CD14 (\%)

CD73 (\%)

CD90 (\%)

CD13 (\%)
Mean \pm SEM

$85.3 \pm 11.3$

$94.9 \pm 1.2$

Mean \pm SEM

$0.3 \pm 0.1$

$0.5 \pm 0.2$

$98.4 \pm 1.0$

$99.3 \pm 0.2$

$99.5 \pm 0.1$ 


\begin{tabular}{|c|c|c|c|c|c|}
\hline $\begin{array}{c}\text { SAE } \\
\text { Number* }\end{array}$ & $\begin{array}{l}\text { Time of } \\
\text { SAE }\end{array}$ & Description of SAE & $\begin{array}{l}\text { Defining } \\
\text { Criteria }\end{array}$ & $\begin{array}{l}\text { Relationship } \\
\text { to Procedure }\end{array}$ & Imputability \\
\hline 1 & M9 & Nasal surgery assessment & $\begin{array}{c}\text { Required } \\
\text { in-patient } \\
\text { hospitalization }\end{array}$ & Not related & Other \\
\hline 2 & M13 & $\begin{array}{l}\text { Hospitalization for planned } \\
\text { coronary angiogram }\end{array}$ & $\begin{array}{c}\text { Required } \\
\text { in-patient } \\
\text { hospitalization }\end{array}$ & related & $\begin{array}{c}\text { Disease } \\
\text { progression }\end{array}$ \\
\hline 3 & M17 & $\begin{array}{l}\text { Scheduled hospitalization for } \\
\text { assessment of operability for a } \\
\text { possible mechanical } \\
\text { circulatory support and pre- } \\
\text { transplant assessment }\end{array}$ & $\begin{array}{c}\text { Required } \\
\text { in-patient } \\
\text { hospitalization }\end{array}$ & Not related & $\begin{array}{c}\text { Disease } \\
\text { progression }\end{array}$ \\
\hline 4 & M17 & $\begin{array}{c}\text { Global cardiac } \\
\text { decompensation with } \\
\text { lipothymia and atrial } \\
\text { fibrillation }\end{array}$ & $\begin{array}{c}\text { Required } \\
\text { in-patient } \\
\text { hospitalization }\end{array}$ & Not related & $\begin{array}{c}\text { Disease } \\
\text { progression }\end{array}$ \\
\hline 5 & M18 & $\begin{array}{l}\text { Renal failure, anaemia, and } \\
\text { slight cardiac overload after } \\
\text { rehydration and decrease of } \\
\text { diuretic doses }\end{array}$ & $\begin{array}{c}\text { Required } \\
\text { in-patient } \\
\text { hospitalization }\end{array}$ & Not related & $\begin{array}{l}\text { Evolution of other } \\
\text { pre-existing disease }\end{array}$ \\
\hline 6 & M20 & $\begin{array}{l}\text { Scheduled hospitalization for } \\
\text { right catheterization and } \\
\text { inscription on transplant } \\
\text { waiting list }\end{array}$ & $\begin{array}{c}\text { Required } \\
\text { in-patient } \\
\text { hospitalization }\end{array}$ & Not related & $\begin{array}{c}\text { Disease } \\
\text { progression }\end{array}$ \\
\hline 7 & M20 & $\begin{array}{l}\text { Acute pulmonary edema on } \\
\text { severe ischemic } \\
\text { cardiomyopathy }\end{array}$ & $\begin{array}{c}\text { Required } \\
\text { in-patient } \\
\text { hospitalization }\end{array}$ & Not related & $\begin{array}{c}\text { Disease } \\
\text { progression }\end{array}$ \\
\hline 8 & M21 & $\begin{array}{l}\text { Scheduled hospitalization for } \\
\text { reassessment of PAD, } \\
\text { revascularization of superficial } \\
\text { femoral and tibial right arteries } \\
\text { with correct result }\end{array}$ & $\begin{array}{c}\text { Required } \\
\text { in-patient } \\
\text { hospitalization }\end{array}$ & Not related & $\begin{array}{l}\text { Evolution of other } \\
\text { pre-existing disease }\end{array}$ \\
\hline 9 & M22 & $\begin{array}{l}\text { Congestive heart failure: } \\
\text { increased dyspnoea }\end{array}$ & $\begin{array}{c}\text { Required } \\
\text { in-patient } \\
\text { hospitalization }\end{array}$ & Not related & $\begin{array}{c}\text { Disease } \\
\text { progression }\end{array}$ \\
\hline 10 & M22 & $\begin{array}{l}\text { Scheduled hospitalization for } \\
\text { femoral artery stenting in } \\
\text { patient with symptomatic PAD }\end{array}$ & $\begin{array}{c}\text { Required } \\
\text { in-patient } \\
\text { hospitalization }\end{array}$ & Not related & $\begin{array}{l}\text { Evolution of other } \\
\text { pre-existing disease }\end{array}$ \\
\hline 11 & M24 & $\begin{array}{l}\text { Adaptation of diabetic } \\
\text { treatment }\end{array}$ & $\begin{array}{c}\text { Required } \\
\text { in-patient } \\
\text { hospitalization }\end{array}$ & Not related & $\begin{array}{l}\text { Evolution of other } \\
\text { pre-existing disease }\end{array}$ \\
\hline
\end{tabular}

*SAE number 2, 3, 7, and 9 occurred in the same patient; SAE number 5 and 8 occurred in the same patient; SAE number 4 and 11 occurred in the same patient.

M: month, CAD: coronary artery disease, PAD: peripheral artery disease. 
Table 4. Medical Treatment.

\section{Baseline}

$85 \%$

$60.6 \%$

$68 \pm 16.5$

Loop diuretics (furosemide), mean (SEM), mg

Mineralocorticoid receptor antagonists, mean (SEM), mg

Beta-blockers (\% maximal dose*)
M12

P-value

ACE or ARB (\% maximal dose*)

ACE: angiotensin converting enzyme inhibitors, ARB: angiotensin 2 receptor blockers.

*Expressed as the percentage of maximum expected dose for the specific drug administered (ACE: enalapril, perindopril, or ramipril; ARB: candesartan; beta-blockers: carvedilol and bisoprolol). 